\title{
Screening of microfilaricidal effects of plant extracts against Dirofilaria immitis
}

\begin{abstract}
Canine dirofilariasis is a common tropical parasitic disease of companion animals, caused by infestation of Dirofilaria immitis filarids within the pulmonary arteries and extending into the right heart. Increased reports of adverse reactions elicited by current microfilaricidal agents against D. immitis such as neurological disorders, circulatory collapse and potential resistance against these agents, warrant the search for new agents in forms of plant extracts. The use of plant extracts in therapeutic medicine is commonly met with scepticism by the veterinary community, thus the lack of focus on its medical potential. This study evaluated the presence of microfilaricidal activities of the aqueous extracts of Zingiber officinale, Andrographis paniculata and Tinospora crispa Miers on D. immitis in vitro at different concentrations; $10 \mathrm{mg} / \mathrm{ml}, 1 \mathrm{mg} / \mathrm{ml}, 100 \mathrm{lg} / \mathrm{ml}, 10 \mathrm{lg} / \mathrm{ml}$ and $1 \mathrm{lg} / \mathrm{ml}$ within $24 \mathrm{~h}$, by evaluation of relative microfilarial motility as a measure of microfilaricidal activity. All extracts showed microfilaricidal activity with $\mathrm{Z}$. officinale exhibiting the strongest activity overall, followed by A. paniculata and T. crispa Miers. It is speculated that the microfilaricidal mechanism exhibited by these extracts is via spastic paralysis based upon direct observation of the microfilarial motility.
\end{abstract}

Keyword: Dirofilaria immitis, Zingiber officinale, Andrographis paniculata, Tinospora crispa Miers 